\title{
Investigation on the Microstructure, Texture and Magnetostriction of Directionally Solidified $\mathbf{T b}_{0.3} \mathbf{D y}_{\mathbf{0 . 7}} \mathbf{F e}_{1.95-x} \mathbf{V}_{x}$ Alloys
}

\author{
J. Arout Chelvane, Mithun Palit, Himalay Basumatary, \\ S. Banumathy, A. K. Singh, and S. Pandian
}

Defence Metallurgical Research Laboratory, Hyderabad 500058, India

Correspondence should be addressed to J. Arout Chelvane, jarout@yahoo.com

Received 2 November 2011; Revised 31 January 2012; Accepted 2 March 2012

Academic Editor: H. Hosoda

Copyright ( $\odot 2012$ J. Arout Chelvane et al. This is an open access article distributed under the Creative Commons Attribution License, which permits unrestricted use, distribution, and reproduction in any medium, provided the original work is properly cited.

\begin{abstract}
Effect of $\mathrm{V}$ addition on the microstructure and magnetostriction of directionally solidified $\mathrm{Tb}_{0.3} \mathrm{Dy}_{0.7} \mathrm{Fe}_{1.95}$ has been investigated. The microstructure of $\mathrm{V}$ added alloys $\left(\mathrm{Tb}_{0.3} \mathrm{Dy}_{0.7} \mathrm{Fe}_{1.95-x} \mathrm{~V}_{x}\right.$ with $x=0,0.025,0.05$, and 0.075$)$ indicate that $\mathrm{Fe}-50$ at. $\% \mathrm{~V}$ is formed as primary phase, which subsequently undergoes spinodal decomposition. The spinodially decomposed Fe-rich phase reacts with the liquid and forms the matrix phase, ( Tb,Dy) $\mathrm{Fe}_{2}$. The V-rich spinodally decomposed product, on the other hand, exists as remnant phase without undergoing any metallurgical transformation. Texture studies indicate that the grains of $(\mathrm{Tb}, \mathrm{Dy}) \mathrm{Fe}_{2}$ show $\langle 110\rangle /$ rotated $\langle 110\rangle$ and $\langle 112\rangle$ orientations for all compositions investigated in the directionally solidified condition. An improvement in magnetostriction has been noticed for small addition of $\mathrm{V}(x=0.025)$ and with further addition the magnetostrictive property decreases. The formation of additional phases containing vanadium is attributed to be the reason when $\mathrm{V}$ is added in higher concentration $(x>0.025)$ levels.
\end{abstract}

\section{Introduction}

The recent research and development work on Tb-Dy-Febased magnetostrictive material is aimed mostly at improving the magnetostrictive property through (i) grain orientation by directional solidification and (ii) through microstructural modification by selective alloying additions, followed by appropriate heat treatment [1-7]. Directional solidification under high temperature gradient serves to produce a microstructure that consists of mainly the Laves phase, ( $\mathrm{Tb}, \mathrm{Dy}) \mathrm{Fe}_{2}$, and the minor phase (Tb,Dy)-rich with no significant evidence for the coexistence of other phases [4]. While attempting to grow longer rods $(80-100 \mathrm{~mm})$ during directional solidification, maintenance of high temperature gradient as to propitiate such microstructural features will be difficult since the solidification front moves away from the chilled plate, encountering a drop in the temperature gradient. The reduced temperature gradient promotes formation of $(\mathrm{Tb}, \mathrm{Dy}) \mathrm{Fe}_{3}$ as the primary phase and its conversion into ( $\mathrm{Tb}, \mathrm{Dy}) \mathrm{Fe}_{2}$ does not lead to completion due to the sluggishness of the peritectic reaction, $(\mathrm{Tb}, \mathrm{Dy}) \mathrm{Fe}_{3}+$ $\mathrm{L} \rightarrow(\mathrm{Tb}, \mathrm{Dy}) \mathrm{Fe}_{2}$. The unreacted (Tb,Dy) $\mathrm{Fe}_{3}$, therefore, affects the magnetostrictive property of the material [8]. Selective alloying additions are known to cause enhancement in the chosen property by way of suppressing the formation of this deleterious phase. The addition of magnetic elements such as $\mathrm{Co}, \mathrm{Ni}, \mathrm{Mn}$ is known to have less significant effect on the functional property of the material although it profoundly triggers changes in the physical properties such as spin fluctuations, sublattice anisotropy, spin flip meta-magnetism, large magnetocaloric effect [8-10]. On the other hand, addition of non-magnetic elements such as $\mathrm{Nb}$, $\mathrm{Zr}$ and $\mathrm{Ti}$, is known to cause significant improvement in magnetostriction when added in very low concentrations. These refractory elements exhibit a limited or negligible solubility in $\mathrm{Fe}[6,7,11]$. In this context, the other important refractory element, namely, vanadium, which is widely used for modifying the magnetic functions of the materials, 
exhibits larger solubility in Fe and its addition thus assumes significance from the point of view of microstructural modifications accompanied with changes in the functional property of the material. As a continuation of our earlier studies on alloying additions, an investigation was carried out on vanadium addition to $(\mathrm{Tb}, \mathrm{Dy}) \mathrm{Fe}_{1.95}$ and the alloys thus made in grain-oriented form by modified Bridgman technique were characterized for the microstructural features and for the property of magnetostriction.

\section{Experimental Details}

Alloys with nominal composition of $\mathrm{Tb}_{0.3} \mathrm{Dy}_{0.7} \mathrm{Fe}_{1.95-x} \mathrm{~V}_{x}$ with $x=0,0.025,0.05$ and 0.075 were prepared by induction melting the high purity elements under vacuum better than 5 $\times 10^{-5} \mathrm{~m} \cdot$ bar and subsequently casting the liquid metal into cylindrical rods of $20 \mathrm{~mm}$ dia. and $80 \mathrm{~mm}$ long in transparent quartz tubes. The precast alloy was then directionally solidified under vacuum in a directional solidification furnace with a temperature gradient of $100^{\circ} \mathrm{C} / \mathrm{cm}$ and at a growth rate of $70 \mathrm{~cm} / \mathrm{h}$. The microstructural features of the samples were investigated using a Jeol 440i Scanning Electron Microscope (SEM) with Oxford Energy Dispersive Spectrometry (EDS) detector (with a resolution of $136 \mathrm{eV}$ at $\mathrm{Mn} \mathrm{k} \alpha$ ). The evolution of texture during directional solidification was characterized by obtaining incomplete experimental pole figures on the test samples. The test sample, cut perpendicular to the axis of the rod, was placed in a texture goinometer, and rotated around the normal direction $(\phi)$ and transverse direction $(\chi)$ to get the pole figure data. The Inel XRG 3000 diffractometer coupled with curved "position sensitive detector" has been used for this purpose. Providing $\mathrm{Cu}-\mathrm{k} \alpha$ radiation, a continuous translation $( \pm 8 \mathrm{~mm})$ has been employed to cover a large sample area. The property of magnetostriction was measured at ambient condition under d.c. magnetic field using temperature and field compensated resistance strain gauges affixed to the sample surface.

\section{Results and Discussion}

Directionally solidified $\mathrm{Tb}_{0.3} \mathrm{Dy}_{0.7} \mathrm{Fe}_{1.95-x} \mathrm{~V}_{x}$ alloys with $x=$ $0,0.025,0.05$, and 0.075 are found to form in C15 type cubic Laves phase structure. The crystallographic details for the Laves phase structure is given in Table 1 .

3.1. Magnetostriction. The variation of room temperature magnetostriction against applied dc magnetic field for the directionally solidified $\mathrm{Tb}_{0.3} \mathrm{Dy}_{0.7} \mathrm{Fe}_{1.95-x} \mathrm{~V}_{x}[x=0-0.075]$ alloys is shown in Figure 1. A significant improvement in the property is seen only for the addition of $x=0.025$. For higher concentrations $(x>0.025)$ of $\mathrm{V}$ awddition, the property decreases as compared to that of the parent alloy $(x=0)$. Alloying additions with $\mathrm{Nb}$ and $\mathrm{Ti}$ to $\mathrm{Tb}_{0.3} \mathrm{Dy}_{0.7} \mathrm{Fe}_{1.95}$ too resulted in a similar improvement in magnetostriction $[6,7]$.

3.2. Microstructure and Phase Relations. The microstructural features observed on the DS samples are shown in Figure 2.

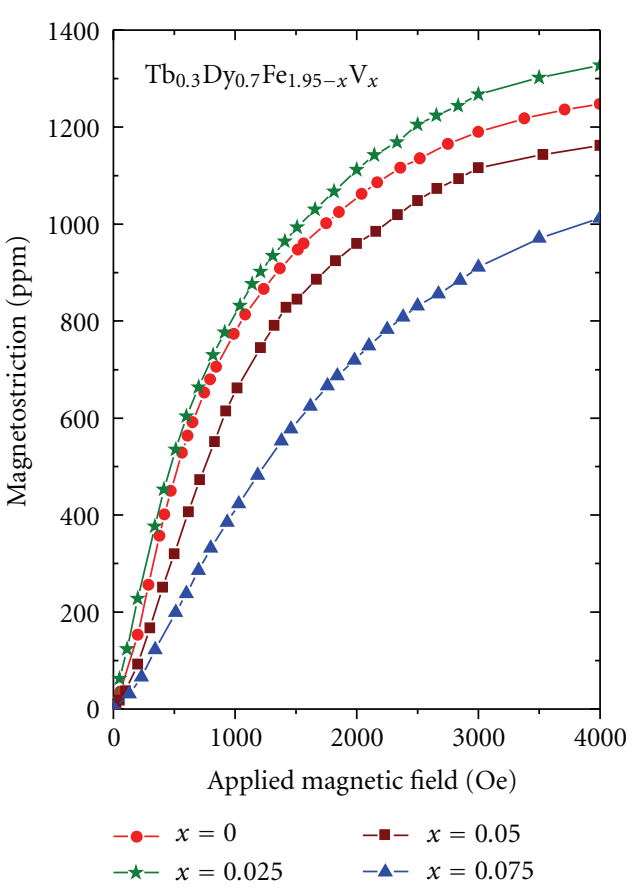

FIGURE 1: Magnetostriction curves of directionally solidified $\mathrm{Tb}_{0.3} \mathrm{Dy}_{0.7} \mathrm{Fe}_{1.95-x} \mathrm{~V}_{x}$ alloys with $x=0,0.025,0.05$ and 0.075 measured as a function of applied d.c magnetic field.

TABLe 1: Crystallographic details of cubic Laves phase (Tb,Dy) $\mathrm{Fe}_{2}$ structure.

\begin{tabular}{|c|c|c|c|c|c|}
\hline & Struct & : cubic (FC & & & \\
\hline & Space group: $\mathrm{Fd} \overline{3} \mathrm{n}$ & $\mathrm{O}_{\mathrm{h}}^{7}: 24$ ato & per & it cell & \\
\hline & Pea & n No.: cF24 & & & \\
\hline & & $=7.32 \AA$ & & & \\
\hline & Ato & c positions: & & & \\
\hline Atoms & Wyckoff notation & Symmetry & $x$ & $y$ & $z$ \\
\hline $\mathrm{Tb} / \mathrm{Dy}$ & $8 \mathrm{a}$ & $\overline{4} 3 \mathrm{~m}$ & 0 & 0 & 0 \\
\hline $\mathrm{Fe}$ & $16 \mathrm{~d}$ & $\overline{3} \mathrm{~m}$ & $5 / 8$ & $5 / 8$ & $5 / 8$ \\
\hline
\end{tabular}

The parent alloy exhibits ( $\mathrm{Tb}, \mathrm{Dy}) \mathrm{Fe}_{2}$ as the matrix phase which is formed by the peritectic reaction of $\mathrm{L}+(\mathrm{Tb}, \mathrm{Dy}) \mathrm{Fe}_{3}$. The (Tb,Dy)-rich and some unreacted (Tb,Dy)Fe 3 are also present in the microstructure. As a consequential effect of addition of $\mathrm{V}$, the properitectic ( $\mathrm{Tb}, \mathrm{Dy}) \mathrm{Fe}_{3}$ is not formed and instead a new phase with $\mathrm{V}$ as a constituent element is formed. The volume fraction of the new phase increases when the concentration of $\mathrm{V}$ is increased in the alloy. A compilation of solidification sequence that seems to be occurring in the alloy compositions investigated is presented in Table 2. The solidification sequence indicates that the Vcontaining phase shifts the composition of the liquid towards the (Tb,Dy) — rich side aiding congruent solidification of $(\mathrm{Tb}, \mathrm{Dy})(\mathrm{Fe}, \mathrm{V})_{2}$ phase. These results are in concurrence with our earlier results on $\mathrm{Nb}$ and $\mathrm{Ti}$ additions which also suppressed the volume fraction of $(\mathrm{Tb}, \mathrm{Dy}) \mathrm{Fe}_{3}$ owing to the formation of Laves phases, namely, $\mathrm{NbFe}_{2}$ and $\mathrm{TiFe}_{2}$ respectively as primary phases. 


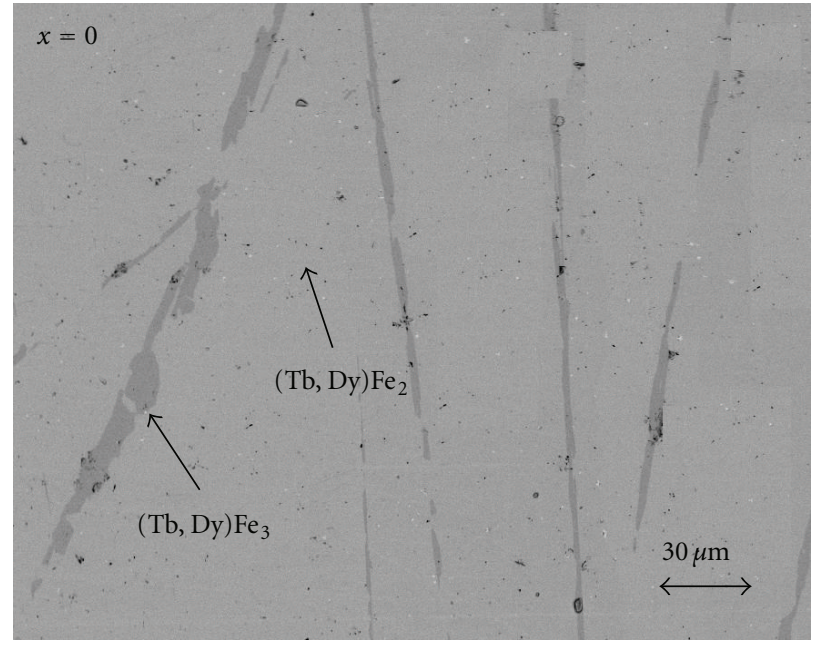

(a)

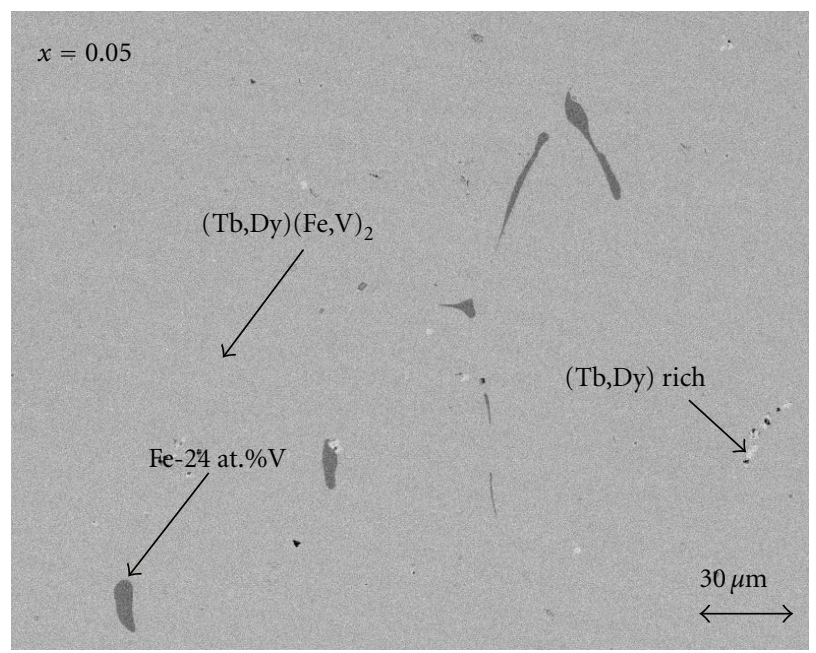

(c)

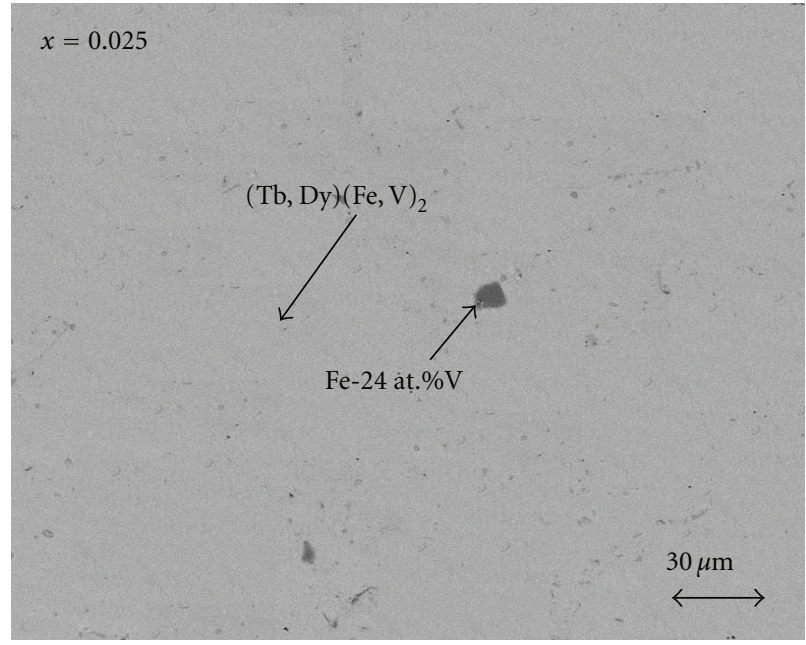

(b)

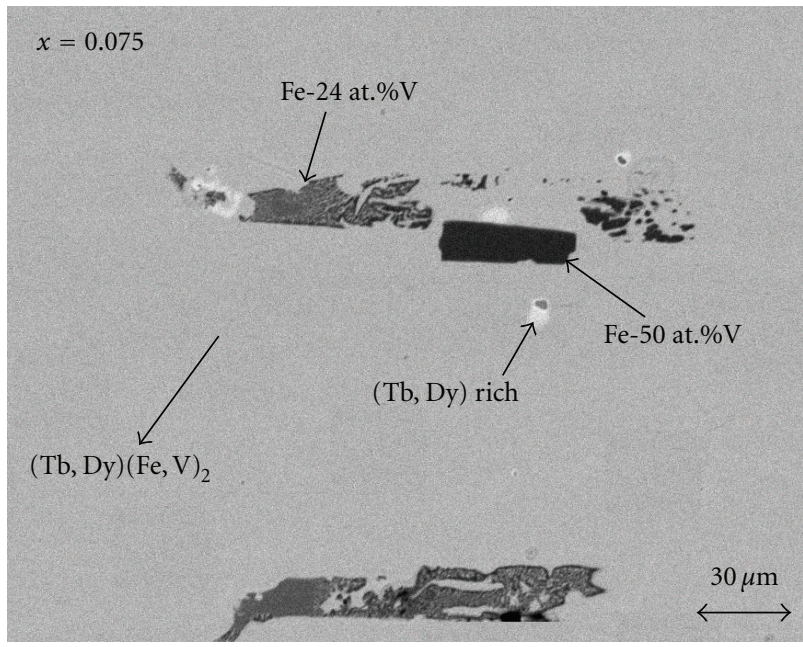

(d)

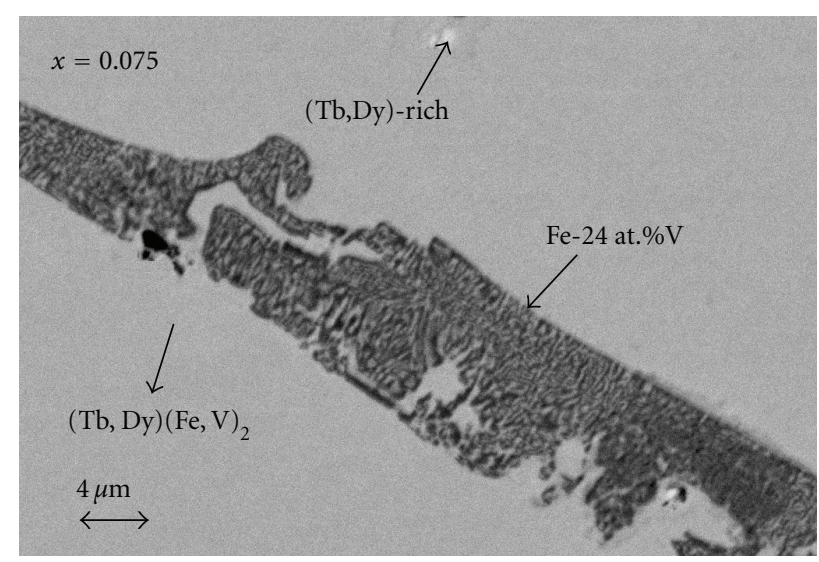

(e)

FIgURE 2: Back-scattered electron images of directionally solidified $\mathrm{Tb}_{0.3} \mathrm{Dy}_{0.7} \mathrm{Fe}_{1.95-x} \mathrm{Ti}_{x}$ alloys with $x=0,0.025,0.05$, and 0.075 . 


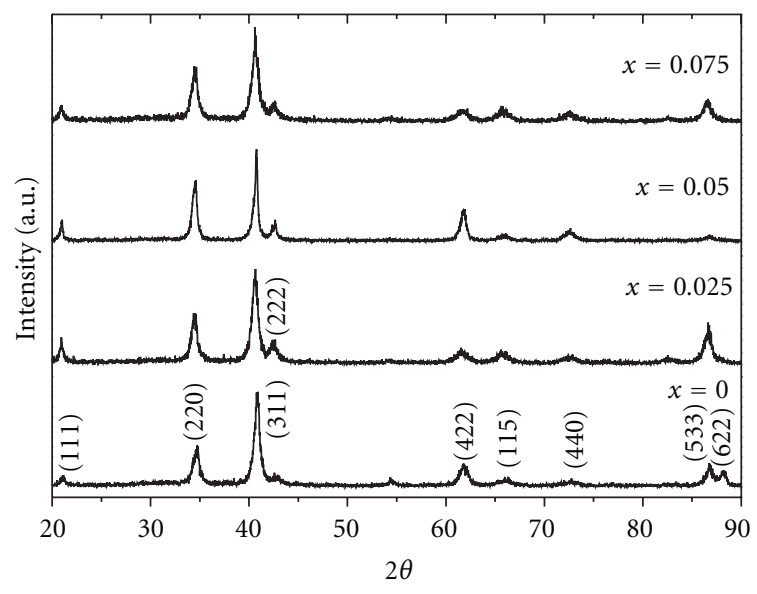

FIGURE 3: X-ray diffraction patterns taken on the transverse section of the directionally solidified $\mathrm{Tb}_{0.3} \mathrm{Dy}_{0.7} \mathrm{Fe}_{1.95-x} \mathrm{~V}_{x}$ alloys with $x=0$, $0.025,0.05$, and 0.075 .

TABLE 2: Solidification sequence of $\mathrm{Tb}_{0.3} \mathrm{Dy}_{0.7} \mathrm{Fe}_{1.95-x} \mathrm{~V}_{x}(x=0$, $0.025,0.05$ and 0.075$)$ alloys.

\begin{tabular}{|c|c|c|}
\hline$x=0$ & $X=0.025$ and 0.05 & $X=0.075$ \\
\hline $\mathrm{L}$ & $\mathrm{L}$ & $\mathrm{L}$ \\
\hline$\downarrow$ & $\downarrow$ & $\downarrow$ \\
\hline $\mathrm{L}+(\mathrm{Tb}, \mathrm{Dy}) \mathrm{Fe}_{3}$ & $\begin{array}{l}\mathrm{L}+\mathrm{Fe}-50 \text { at. } \% \mathrm{~V} \\
\text { solid solution }\end{array}$ & $\begin{array}{c}\mathrm{L}+\mathrm{Fe}-50 \text { at. } \% \mathrm{~V} \text { solid } \\
\text { solution }\end{array}$ \\
\hline$\downarrow$ & $\downarrow$ & $\downarrow$ \\
\hline \multirow[t]{5}{*}{$\begin{array}{l}(\mathrm{Tb}, \mathrm{Dy}) \mathrm{Fe}_{2}+ \\
(\mathrm{Tb}, \mathrm{Dy}) \text {-rich }+ \\
\text { unreacted (Tb,Dy) } \\
\mathrm{Fe}_{3}\end{array}$} & $\begin{array}{c}\mathrm{L}+\mathrm{Fe} \text {-rich }(\mathrm{Fe}, \mathrm{V}) \\
\text { solid solution }+ \\
\mathrm{V} \text {-rich }(\mathrm{Fe}, \mathrm{V}) \text { solid } \\
\text { solution }\end{array}$ & $\begin{array}{c}\mathrm{L}+\mathrm{Fe}-\text { rich }(\mathrm{Fe}, \mathrm{V}) \text { solid } \\
\text { solution }+\mathrm{V} \text {-rich }(\mathrm{Fe}, \mathrm{V}) \\
\text { solid solution }+ \\
\text { un-decomposed } \\
\text { Fe-50 at.\% V solid } \\
\text { solution }\end{array}$ \\
\hline & $\downarrow$ & $\downarrow$ \\
\hline & $\begin{array}{l}\mathrm{L}+\mathrm{V} \text {-rich }(\mathrm{Fe}, \mathrm{V}) \\
\text { solid solution }\end{array}$ & $\begin{array}{c}\mathrm{L}+\mathrm{V} \text {-rich }(\mathrm{Fe}, \mathrm{V}) \text { solid } \\
\text { solution }+ \\
\text { un-decomposed } \\
\mathrm{Fe}-50 \text { at. } \% \text { V solid } \\
\text { solution }\end{array}$ \\
\hline & $\downarrow$ & $\downarrow$ \\
\hline & $\begin{array}{c}(\mathrm{Tb}, \mathrm{Dy})(\mathrm{Fe}, \mathrm{V})_{2}+ \\
(\mathrm{Tb}, \mathrm{Dy})-\mathrm{rich}+ \\
\text { V-rich }(\mathrm{Fe}, \mathrm{V}) \text { solid } \\
\text { solution }\end{array}$ & $\begin{array}{c}(\mathrm{Tb}, \mathrm{Dy})(\mathrm{Fe}, \mathrm{V})_{2}+ \\
(\mathrm{Tb}, \mathrm{Dy}) \text {-rich }+\mathrm{V} \text {-rich } \\
(\mathrm{Fe}, \mathrm{V}) \text { solid solution }+ \\
\text { undecomposed } \\
\text { Fe-50 at.\% V solid } \\
\text { solution }\end{array}$ \\
\hline
\end{tabular}

The morphology of Fe-50 at.\% V phase with distinct edge contours as seen in the microstructure of the alloy with $x=0.075$ indicates that $\mathrm{Fe}-50$ at. $\% \mathrm{~V}$ phase is formed as the primary phase. The primary phase undergoes spinodal decomposition into Fe-rich and V-rich phases at a temperature intermediate between the formation temperature of the primary phase and the peritectic temperature of (Tb,Dy) $\mathrm{Fe}_{2}$. While Fe-rich phase subsequently combines with the liquid phase and forms ( $\mathrm{Tb}, \mathrm{Dy}) \mathrm{Fe}_{2}$ through congruent solidification, the remnant V-rich phase does not undergo any reaction or phase modification. The remnant $\mathrm{V}$ rich $(\mathrm{Fe}, \mathrm{V})$ solid solution appears as colony of alternate band structures in $x=0.075$, having an average composition of $\mathrm{Fe}-24$ at.\% V. Individual microchemistry of alternate bands could not be determined as the size of bands is beyond the resolution of microchemical analysis through SEM-EDS. In $x=0.025$ and 0.05 alloys the primary phase Fe-50 at.\% $\mathrm{V}$ almost undergoes complete spinodal decomposition due to their formation in small volume fraction. However, the banded structure could not be observed in BSE images of $x=0.025$ and 0.05 alloys owing to their fine morphology. Since, spinodal decomposition is a diffusion controlled phase transformation, it could not initiate substantially in every primary Fe-50 at. $\% \mathrm{~V}$ phase of $x=0.075$ alloy, because of short duration of time available during solidification.

3.3. Texture. The X-ray diffraction patterns and X-ray pole figures obtained from the directionally solidified $\mathrm{Tb}_{0.3} \mathrm{Dy}_{0.7} \mathrm{Fe}_{1.95-x} \mathrm{~V}_{x}$ with $x=0,0.025,0.05$ and 0.075 rods are shown in Figures 3 and 4. The parent alloy indicates a strong prevalence of $\langle 110\rangle$ and $\langle 112\rangle$ texture components as seen from (220), (113), and (422) pole figures, while the alloy with $x=0.025$ shows presence of strong $\langle 110\rangle$ and $\langle 113\rangle /$ rotated $\langle 112\rangle\left(\langle 113\rangle \sim 10^{\circ}\right.$ away from $\left.\langle 112\rangle\right)$ texture components, which are favorable for deriving large magnetostriction. The high intensity locations in (220), (422) and (113) pole figures for $x=0.05$ and 0.075 alloys also show co-existence of $\langle 110\rangle$, rotated $\langle 112\rangle$ and $\langle 112\rangle$ texture components similar to those observed in $x=0.025$ sample. Thus, it is seen from the pole figure analysis that with the addition of $\mathrm{V}$, the texture components remain almost similar.

The microstructural and texture studies, therefore, indicate that the improvement in magnetostriction at low $\mathrm{V}$ concentration $(x<0.05)$ is due to the reduction in the volume fraction of the detrimental properitectic $(\mathrm{Tb}, \mathrm{Dy}) \mathrm{Fe}_{3}$ phase and the presence of strong $\langle 110\rangle /$ rotated $\langle 110\rangle$ and $\langle 112\rangle$ grain orientation of (Tb,Dy) $\mathrm{Fe}_{2}$ phase. At higher concentration of $\mathrm{V}$, however, the volume fraction of the $(\mathrm{Fe}, \mathrm{V})$ solid solution increases, causing detrimental effect to the magnetostriction.

\section{Summary and Conclusions}

Alloys of $\mathrm{Tb}_{0.3} \mathrm{Dy}_{0.7} \mathrm{Fe}_{1.95-x} \mathrm{~V}_{x}$ with $x=0,0.025,0.05$, and 0.075 were prepared by directional solidification and investigated for microstructural features, grain orientation and for static magnetostriction as function of applied magnetic field. The improvement in magnetostriction has been realized only for a small addition of $\mathrm{V}(x=0.025)$. For larger additions $(x=0.05$ and 0.1$)$ deterioration in the property has been noticed. The formation of $(\mathrm{Fe}, \mathrm{V})$ as the primary phase appears to be causing the detrimental effect to the magnetostrictive property even while suppressing the formation of the deleterious $(\mathrm{Tb}, \mathrm{Dy}) \mathrm{Fe}_{3}$. The microstrctural features provide an evidence that the primary phase $(\mathrm{Fe}, \mathrm{V})$ undergoes spinodal decomposition above the peritectic temperature of $(\mathrm{Tb}, \mathrm{Dy}) \mathrm{Fe}_{2}$. The grain orientation, which is predominately $\langle 110\rangle$ and $\langle 112\rangle$, seems to emerge 

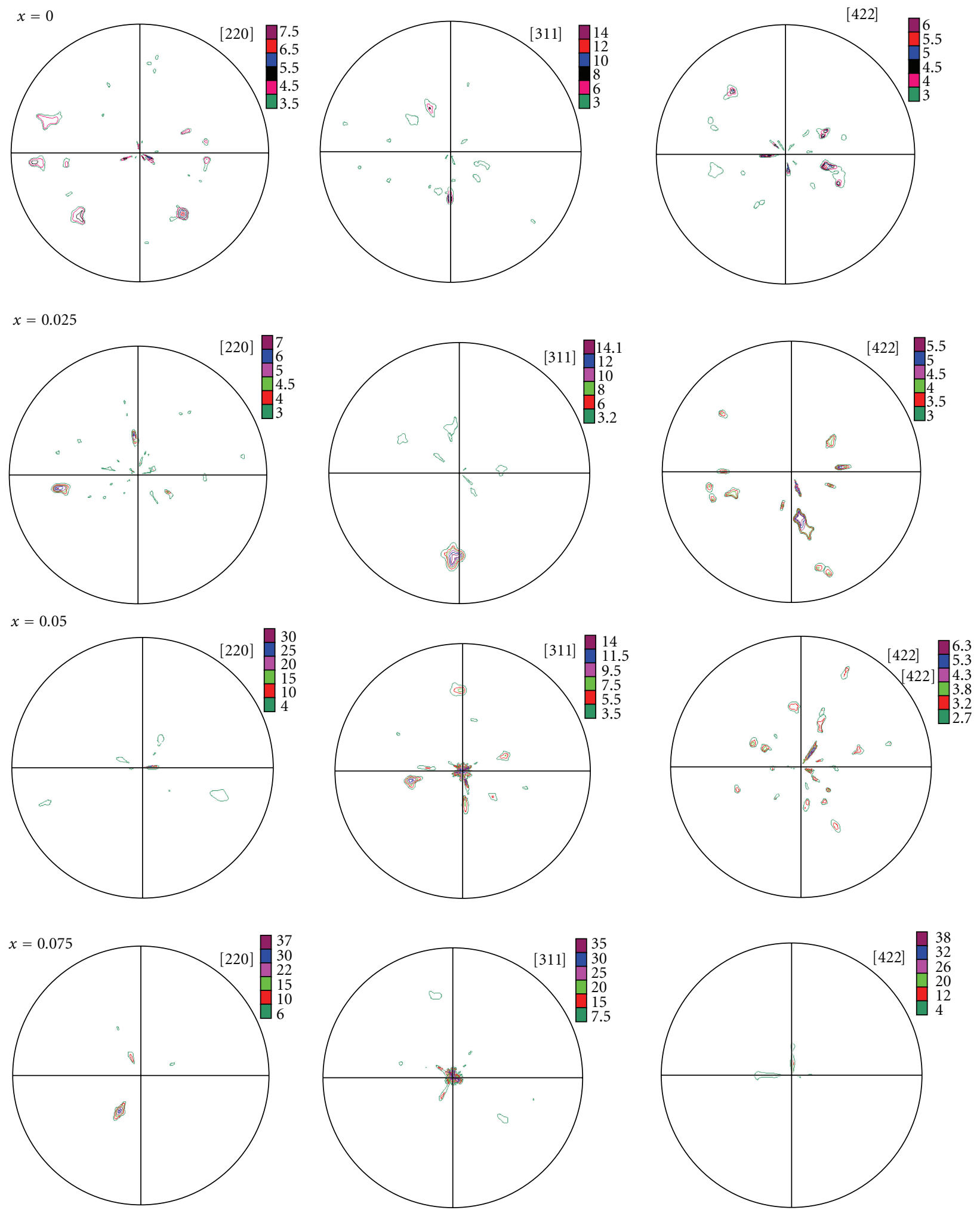

Figure 4: (220), (311), and (422) pole figures taken on transverse section of the directionally solidified $\mathrm{Tb}_{0.3} \mathrm{Dy}_{0.7} \mathrm{Fe}_{1.95-x} \mathrm{~V}_{x}$ alloys with $x=0$, $0.025,0.05$, and 0.075 . 
due to directional solidification and addition of $\mathrm{V}$ has no detrimental effect on altering this orientation.

\section{Acknowledgments}

The authors wish to thank the Defence Research and Development Organization for the financial support and the Director, Defence Metallurgical Research Laboratory, for his encouragement and permission to publish this work.

\section{References}

[1] D. J. Jiles, "The development of highly magnetostrictive rare earth-iron alloys ," Journal of Physics D, vol. 27, no. 1, 1994.

[2] W. Mei, T. Okane, T. Umeda, and S. Zhou, "Directional solidification of Tb-Dy-Fe magnetostrictive alloy," Journal of Alloys and Compounds, vol. 248, no. 1-2, pp. 151-158, 1997.

[3] J. D. Verhoeven, E. D. Gibson, O. D. McMasters, and H. H. Baker, "The growth of single crystal terfenol-D crystals," Metallurgical Transactions A, vol. 18, no. 3, pp. 223-231, 1987.

[4] M. Palit, S. Pandian, R. Balamuralikrishnan et al., "Microstructure and magnetostriction of $\mathrm{Tb}_{0.3} \mathrm{Dy}_{0.7} \mathrm{Fe}_{1.95}$ prepared under different solidification conditions by zoning and modified Bridgman techniques," Journal of Applied Physics, vol. 100, no. 7, Article ID 074913, 2006.

[5] C. Ji, J. Li, W. Ma, and Y. Zhou, "Preparation of Terfenol$\mathrm{D}$ with precise $\langle 110\rangle$ orientation and observation of the oriented growth crystal morphology," Journal of Alloys and Compounds, vol. 333, no. 1-2, pp. 291-295, 2002.

[6] M. Palit, J. Arout Chelvane, H. Basumatary, S. Pandian, and V. Chandrasekaran, "The effect of $\mathrm{Nb}$ and $\mathrm{Zr}$ addition on the microstructural features and magnetic properties of $\mathrm{Tb}_{0.3} \mathrm{Dy}_{0.7} \mathrm{Fe}_{1.95}$," Scripta Materialia, vol. 60, no. 1, pp. 56-59, 2009.

[7] J. Arout Chelvane, M. Palit, H. Basumatary, S. Pandian, and V. Chandrasekaran, "Effects of Ti addition on the microstructure and magnetic properties of magnetostrictive Tb-Dy-Fe alloys," Scripta Materialia, vol. 61, no. 5, pp. 548-551, 2009.

[8] M. Palit, J. Arout Chelvane, H. Basumatary et al., "Comparative effect of texture and microstructure on the magnetostriction of directionally solidified $\mathrm{Tb}_{0.3} \mathrm{Dy}_{0.7} \mathrm{Fe}_{1.95}$ alloy," Intermetallics, vol. 18, no. 5, pp. 1027-1032, 2010.

[9] S. Kishore, G. Markandeyulu, and K. V. S. Rama Rao, "Spin-flip metamagnetism in the laves phase compounds $\mathrm{Dy}_{0.73} \mathrm{~Tb}_{0.27} \mathrm{Fe}_{2-x} \mathrm{Co}_{x} \mathrm{H}_{n}$," Solid State Communications, vol. 108, no. 5, pp. 313-318, 1998.

[10] M. Senthil Kumar, K. V. Reddy, and K. V. S. Rama Rao, "Observation of domain wall pinning in $\mathrm{Dy}_{0.73} \mathrm{~Tb}_{0.27} \mathrm{Fe}_{2-x} N i_{\mathrm{x}}$ and $\mathrm{Ho}_{0.85} \mathrm{~Tb}_{0.15} \mathrm{Fe}_{2-y} \mathrm{Ni}_{y}$ systems," IEEE Transactions on Magnetics, vol. 31, no. 6, pp. 4160-4162, 1995.

[11] J. Arout Chelvane, M. Palit, H. Basumatary et al., "Evolution of microstructure and texture in directionally solidified magnetostrictive $\mathrm{Tb}_{0.3} \mathrm{Dy}_{0.7} \mathrm{Fe}_{1.95-x} \mathrm{Ti}_{x}[X=0,0.025,0.05$ and 0.075$]$ alloys," Journal of Alloys and Compounds, vol. 492, no. 1-2, pp. 731-734, 2010. 

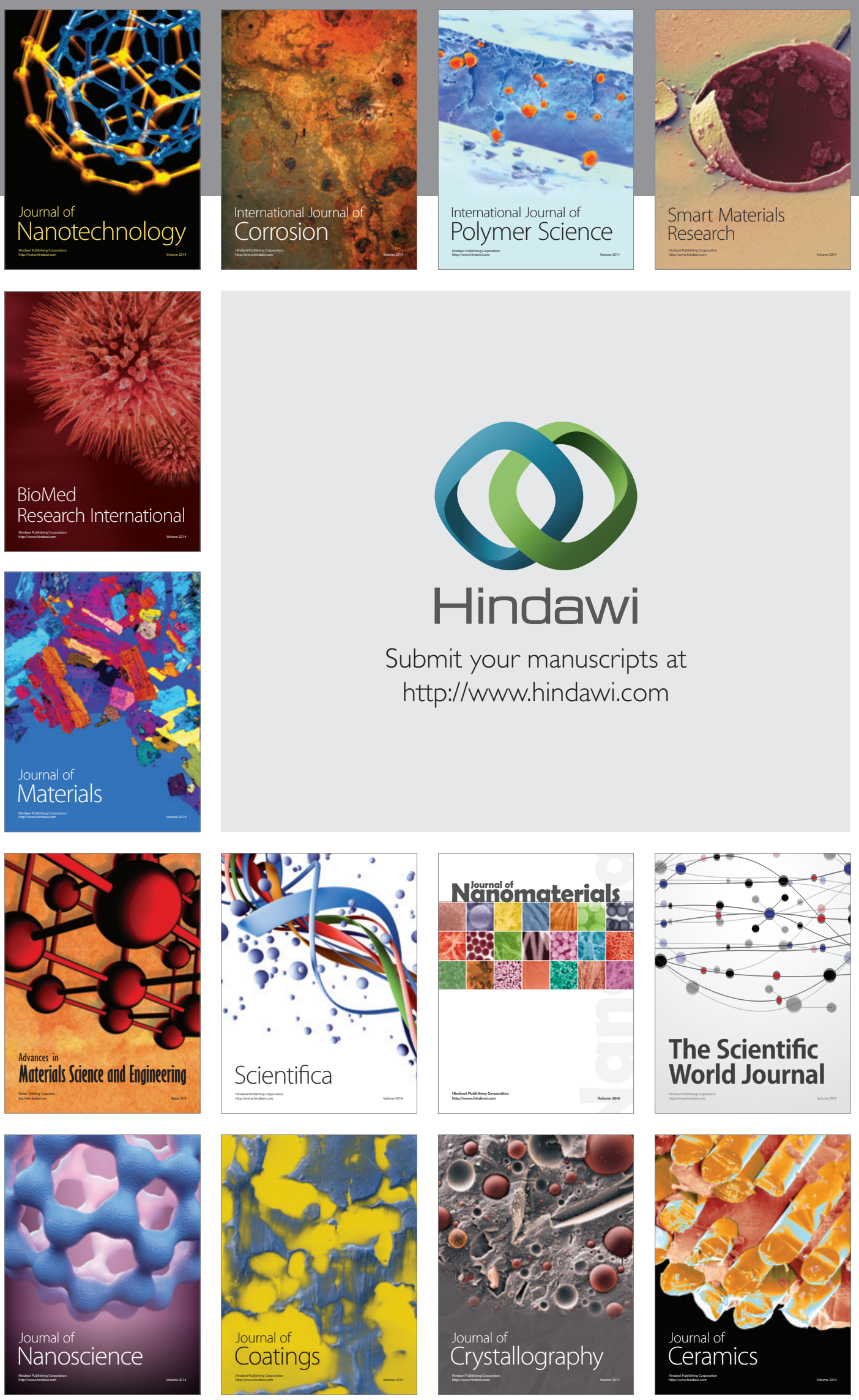

The Scientific World Journal

Submit your manuscripts at

http://www.hindawi.com

\section{World Journal}

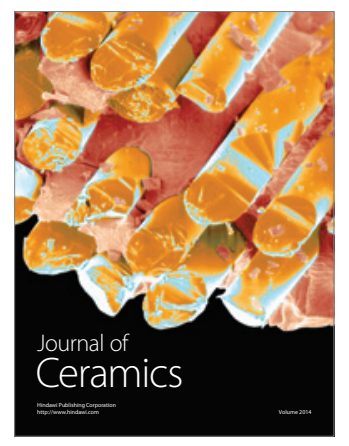

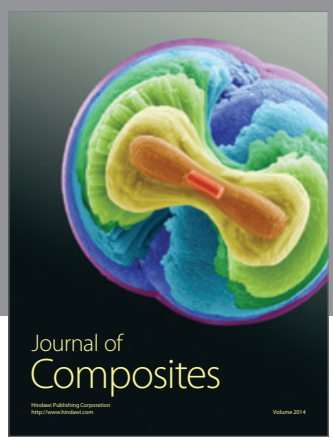
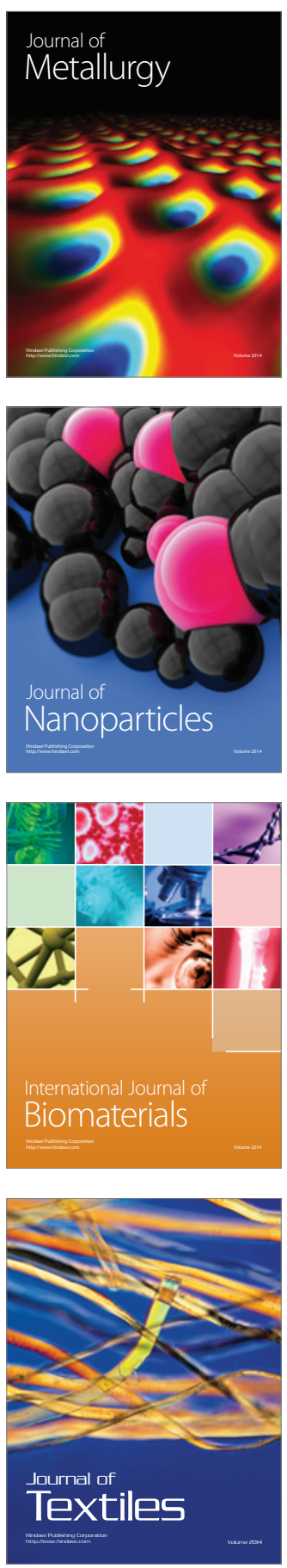